\title{
Future Directions for Smart Grid: A Conceptual Model
}

\author{
Ke-Zhou LI ${ }^{1, a,{ }^{*}}$, Lai-Leng LAO ${ }^{1}$, Yu-Qiang GUO ${ }^{1}$ \\ ${ }^{1} S c h o o l$ of Business, Macau University of Science and Technology, Taipa, Macau \\ achen7455@yahoo.com \\ ${ }^{*}$ Corresponding author
}

Keywords: Future intelligent grid systems, Renewable energy, Low-carbon sources.

\begin{abstract}
Although growth of renewables and other low-carbon energy sources is envisaged, there are many concerns about the flexibility, variability, non-controllability of the sources and the ability to maintain the balance between demands and supply. Then, what will be the future directions for intelligent power Grid systems in China? It is surprised that no research has ever tackled such an important issue before. In order to fill the vacancy, this paper first finds critical success criteria of future intelligent power Grid systems, and then constructs multiple criteria and decision making (MCDM) models to help in identifying the most suitable directions under complex social-economic environments, rapidly-changing technological movement and market demands. After practical investigation, the paper finds that a centralized power Grid system with Grid-aware networks, cloud-computing and multi-purpose Grid applications should be more suitable for China's future development.
\end{abstract}

\section{Introduction}

To achieve a significant reduction in $\mathrm{CO}_{2}$ emissions, renewables and other low-carbon energy sources will become major contributors to the electricity generation systems. Although growth of these sources is envisaged, there are many concerns about the flexibility, variability, non-controllability of the sources and the ability to maintain the balance between demands and supply (Strbac, 2008). Under this kind of situation, the current power infrastructures in both Europe and US are being quickly out of date even with very different policies and socio-economical contexts. Key parts of the solution for both of them seem to be the evolution toward a more intelligent power Grid. Europe's vision is clearly influenced by the concern derived from the wide range of natures and degrees of evolution of the power Grids across European countries. The consequence of this concern is identified in the need to have a flexible, reliable and accessible power Grid, which basically means a power Grid that can fulfill the needs of a wide range of customers and economies (Coll-Mayor et al., 2007). Oppositely, the vision proposed in the US is mainly related to what is still seen as a largely centralized power Grid but with a high integration of demand response and some penetration of distributed power systems used for additional support to the system, all controlled by advanced IT technologies (Coll-Mayor et al., 2007). In summary, the value of services associated with the balancing of demand and supply in the future Grid system is likely to be very significant, and demand is likely to be required to take a significantly more active role in matching electricity generation. Then, what will be the future directions for intelligent power Grid systems in China?

It is surprised that no research has ever tackled such an important issue before. In order to fill the vacancy, this paper first finds critical success criteria of future intelligent power Grid systems, and then constructs multiple criteria and decision making (MCDM) models to help in identifying the most suitable directions under complex social-economic environments, rapidly-changing technological movement and market demands. Most MCDM models, such as conventional analytic network process (ANP), usually adopt pairwise comparison with respect to its network's criteria to rank its final priority. However, synthesizing the introducing positive criteria like benefits $(\mathrm{B})$, opportunities $(\mathrm{O})$ and the introducing negative criteria like costs $(\mathrm{C})$, risks $(\mathrm{R})$ with rating calculation like additive, subtractive and multiplicative is a more instinctive method to a daily life. Accordingly, ANP associated with BOCR is applied in the paper to handle this kind of positive and negative criteria in public-oriented projects. After practical investigation, the paper finds that a centralized power Grid system with Grid-aware networks, 
cloud-computing and multi-purpose Grid applications should be more suitable for China's future development. This paper will help policy makers quickly review surroundings and also identify its potential to support energy strategy in the electricity infrastructure. This paper will also help bureaucrats, entrepreneurs, scientists and other energy experts for identifying international standardization, projects and potential partners in the area of future Grid technologies.

\section{Literature reviews}

The objective of the future Grid computing systems is the integration of heterogeneous computing and data resources with the aim of providing a global computing space (Herrero et al., 2010). A typical Grid system is constituted by four layers (Haque et al., 2011). The most bottom layer, called the fabric layer, consists of servers, clusters, monitors and all other distributed resources around the world.

The second layer, called the core middleware layer, offers all the necessary functions such as scheduling, security, data transfer, trading and communication. It supports efficient management of shared resources through maintaining the supply and demand of distributed resources (Globus, 2006; Rajkumar et al., 2009). The main objective of this layer is to hide the heterogeneous nature and provide a homogeneous and flexible environment to end users. Current Grid developers and practitioners are increasingly realizing the importance of efficient network support. Entire classes of applications would greatly benefit from a network-aware Grid middleware, able to effectively manage the network resource in terms of scheduling, access and use. Conversely, the peculiar requirements of Grid applications provide stimulating drivers for new challenging research towards the development of Grid-aware networks. Cooperation between Grid middleware and network infrastructure driven by a common control plane is a key factor to effectively empower the global Grid platform for the execution of network-intensive applications, requiring massive data transfers, very fast and low-latency connections, and stable and guaranteed transmission rates (Spinnato et al., 2009).

The third layer, called the user middleware layer, provides API (Application Programming Interface), libraries, application development environments and resource mediator, which negotiates between users and providers, and schedules application tasks for execution on global resources (Ian et al., 2005; Tom et al., 2008). Cloud computing is a new concept that has evolved recently from the Grid world (Izakian et al., 2009). Cloud computing is based on a simple business model providing on-demand services, supported by several companies which offer various Cloud services. More recently, many companies have taken up interest in Cloud computing as a way improve flexibility and reduce fixed costs (Yajuan and Xianjia, 2009). The simplicity of the business model and the commercial success of Cloud computing may have caused many companies to move away from Grid computing and adopt Cloud computing instead.

The fourth layer, called the Grid applications layer, is typically developed using the components of user level middleware. This layer supports users to execute their applications on remote resources and collect results from them using web portals or applications such as the Grid Application Toolkit and java Commodity Grid kit (Haque et al., 2011). Many of the current Grid users are "Grid hackers". They are familiar with the Grid technology. They know how to develop and run applications in Linux/Unix environment using programming languages such as $\mathrm{C}$ and Java. They use command-line interfaces (CLI) to run their applications on the Grid. If the Grid wants to be a success story, which it definitely wants, it should involve further users and user communities who do not have the above mentioned knowledge and many of them do not even want to obtain this knowledge. They want to migrate and deploy their calculation, modeling, simulation, and applications on the Grid, to run them with minimum costs and efforts having access to Grid resources in a transparent way (Kacsuk and Terstyanszky, 2008). In addition, Security, trust and privacy issues are of chief importance in Grids, where both resource providers and consumers require guarantees that their information will be protected from malicious attacks and misuse (Arenas and Massonet, 2010).

Based on extensive literatures (Yusuf, et al., 2006; Tom et al., 2008; Yajuan and Xianjia, 2009; Schweiegelshohn et al., 2010; Haque et al., 2011) and the evaluation of the committee, the most important factors for successful Grid systems are as follows: Under benefits, there are criteria: functionality (to what extent the completed product complies with all functionality targets including availability, efficiency and openness, etc.), reliability (to what extent the completed product meets all 
reliability objectives like accuracy, quality and stability, etc.), and usability (to what extent the completed product meets user friendly characteristics like ease of use, easy to repair, easy fault identification, etc.). The criteria under opportunities are scaling capabilities (to what extent the completed product meets the traits of easy expansion and extension including hardware and software, numbers of sites among users and suppliers), learning \& innovation (easy access, learning and sharing of technology and information for all related personnel), and flexibility (compatibility of hardware support, good application software to provide ability to interface, support and manage files and to perform storage, retrieval, manipulation and transmission functions). Under costs are criteria: estimated product price (the estimated product price including hardware, software, installation and maintenance, etc.), estimated research and development spending (estimated sunk expenditure), and estimated foundation spending (the spending incurring from main building construction, backbone construction and Grid connection). The criteria under risks are: concept conflict (different concepts among entrepreneurs, policy makers, and other stakeholders), technical risks (inadequacy in advanced technologies), and cultural differences and geographical mismatch. In order to select the best suitable Grid projects to develop in the subsequent sections, the authors constructed a BOCR framework with twelve critical success criteria.

\section{A case study}

The purpose of the section is to employ the proposed systematic ANP model with BOCR to identify future directions for Grid research and development by comprehensively qualitative and quantitative analyses of the economic, environmental, market and technical performance of alternative options.

In the first step, eleven experts, including bureaucrats, decision-makers, entrepreneurs, scientists and other stakeholders, contributed their professional experience and formed the evaluation committee. Their first task was to select critical success criteria, as described in section 3. The committee also confirmed the firm's strategic criteria as performance, business drivers and Chinese specific need, based on previous literatures and practical experiences (Yusuf, et al., 2006). The relationship of future Grid project among final goal, strategic criteria, merits, criteria and alternatives is structured by evaluation committee.

The relationship can be divided into two networks: the control network and the BOCR network. The first level of the control network contains the goal, the selection of the best suitable project. In the second level, three strategic criteria are considered; namely, performance, business driver, and Chinese specific need. Performance concerns the capabilities of the technology for delivering the expected results in variant processing environments such as functionality and usability. Business drivers are defined as the expectations of stakeholders and consist of opinions of bureaucrat, scientists or other energy experts, for instance time to business operations, learning and innovation, risks and costs. Chinese specific need considers whether the advanced technologies satisfy Chinese needs in compared with other competitors. In the third level, there are benefits $(\mathrm{B})$, opportunities $(\mathrm{O})$, costs $(\mathrm{C})$, and risks $(\mathrm{R})$ four merits. The purpose of the control network is to calculate the priorities of the four merits.

The BOCR network has the same goal as the control network does, and the purpose of this network is to calculate the priorities of alternatives. The second level of the network composes of the four merits: benefits, opportunities, costs and risks. The BOCR network can be further divided into four sub-networks: benefits sub-network, opportunities sub-network, costs sub-network, and risks sub-network. In the third level of the network, twelve selected criteria in section 3 are applied here to evaluate each alternative. Under merit benefits, there are three criteria, group factors (a) through (c). Under merit opportunities, there are three detailed criteria, group factor (d), (e) and (f). Group factors (g), (h) and (i) are the criteria of merit costs and group factors (j), (k) and (l) are the criteria of merit risks.

A typical Grid system is constituted by four layers (Herrero et al., 2010; Haque et al., 2011). There are two main alternatives including a centralized Grid power system and a distributed Grid power system necessary to be prioritized in the bottom layer. In the second layer (the core middleware layer), two major developing directions including a network-aware Grid middleware and a Grid-aware network need to be selected. There are two main functions including cloud computing and Grid computing necessary to be prioritized in the third layer (the user middleware layer). In the fourth layer (the Grid applications layer), two major business operations approaches including a single-purpose mode (the power-oriented business operations only) and a multi-purpose mode (including video entertainments, building automation etc.) 
need to be selected. Totally, there are sixteen combinations; however, only five combinations, passed the first-round selection by the evaluation committee, and they are represented as combination A, B, C, D and E. A questionnaire is constructed, and the members of the evaluation committee are invited to contribute their professional experience. Based on the collected opinions of the experts and the proposed model, the performance of the five combinations can be generated.

In the first part of the model, experts are asked to evaluate the priorities of benefits, opportunities, costs and risks. Form a pairwise comparison matrix to evaluate the three strategic criteria, and calculate the priorities of the strategic criteria. The consistency property of the matrix is examined. Delphi method is applied to obtain a consensus among the members. The final pairwise comparison of the experts on the three strategic criteria with respect to the goal is obtained. Next, experts are asked to assess BOCR according to strategic criteria by the five step scale. The ratings of the four merits on strategic criteria by Delphi method are obtained. The normalized weights for benefits, opportunities, costs, and risks are $0.3652,0.2874,0.1934$, and 0.1540 respectively.

In the second part of the model, the priorities of the combinations under each merit are calculated. There are four sub-networks, namely benefits, opportunities, costs, and risks. The relative importance weights of criteria with respect to the same upper level merit, the interdependence priorities among the criteria that have the same upper-level merit are calculated using the Delphi pairwise comparison results. The synthesized priorities of criteria after taking into account the inter-relationship among criteria. Under the benefits merit, the most important criterion, out of three criteria, is functionality, with a priority of 0.557. This means that the major benefit concern for the firm in having the project is to have a good function to operate. Under the opportunities merit, scaling with value of 0.534 is the most important criterion. This implies that a system that can be scalable is essential for the firm. Under the costs merit, product price with a value of 0.514 is the major concern. Under the risks merit, technical risk with a value of 0.591 is very important. This means that the firm worries more about the possibility that it does not have adequate technologies and capability to handle the system.

The performance results of different combinations under various criteria, however, are collected from each expert in order to limit the number of pairwise comparisons (Saaty 1980). For the criteria under merits benefits and opportunities, the higher the score, the better the performance of the combination is. On the other hand, product price, R\&D spending and foundation spending are quantitative criteria under costs. The larger the amount is, the worse the performance of the combination is. Similarly, for the criteria under merit risks, the higher the score, the worse the performance of the combinations is. The synthesized performance value of each combination on each criterion is calculated by geometric averaging the results from all the experts. These performance values are further transformed into a number from zero to one by dividing the performance value of a combination on a criterion by the largest performance value among all combinations on the same criterion. The above performance values of combinations and the priorities of criteria are synthesized to obtain the overall performance of each combination under each merit.

Table 1 Final synthesis of priorities for different combinations

\begin{tabular}{|c|c|c|c|c|c|c|c|c|c|c|}
\hline \multirow{2}{*}{$\begin{array}{l}\text { Synthesizing } \\
\text { methods }\end{array}$} & \multicolumn{2}{|c|}{ Additive } & \multicolumn{2}{|c|}{$\begin{array}{c}\text { Probabilistic } \\
\text { additive }\end{array}$} & \multicolumn{2}{|c|}{ Subtractive } & \multicolumn{2}{|c|}{$\begin{array}{l}\text { Multiplicative } \\
\text { priority powers }\end{array}$} & \multicolumn{2}{|c|}{ Multiplicative } \\
\hline & Priority & Rank & Priority & Rank & Priority & Rank & Priority & Rank & Priority & Rank \\
\hline $\begin{array}{c}\text { Combination } \\
\text { A }\end{array}$ & 0.21 & 2 & 0.4 & 3 & 0.0 & 3 & 0.2 & 2 & 1.1561 & 2 \\
\hline $\begin{array}{c}\text { Combination } \\
\text { B }\end{array}$ & 0.2231 & 1 & 0.4871 & 1 & 0.0453 & 1 & 0.2237 & 1 & 1.1874 & 1 \\
\hline Combination & 0 & 4 & 0.4 & 4 & 0 & 4 & 3 & 4 & 0.5 & 4 \\
\hline $\begin{array}{c}\text { D } \\
\text { Combination }\end{array}$ & 0.2075 & 3 & 0.4658 & 2 & 0.0387 & 2 & 0.2082 & 3 & 1.1298 & 3 \\
\hline $\mathrm{E}$ & 0.1872 & 5 & 0.4482 & 5 & 0.0194 & 5 & 0.1871 & 5 & 0.8846 & 5 \\
\hline
\end{tabular}


The final ranking of the combinations are calculated by the five methods to combine the scores of each combination under $\mathrm{B}, \mathrm{O}, \mathrm{C}$ and $\mathrm{R}$. The result is as shown in Table 1. Under all five methods of synthesizing the scores of combinations, combination $\mathrm{B}$ ranks the first. While combination $\mathrm{C}$ and combination E always stay respectively as the fourth and the last alternatives, combination $\mathrm{A}$ and combination $\mathrm{D}$ take turns in the ranking of the second and the third. Under additive, multiplicative, and multiplicative priority powers methods, combination $\mathrm{A}$ is the second best, and combination $\mathrm{D}$ is the third. However, under probabilistic additive and subtractive methods, the opposite is true. Such a result is because the combinations of the two alternatives are similar except for those of the core middleware layer and the user middleware layer, and the overall scores of the two combinations are not significantly different under all the methods of calculation. Combination B, the most suitable Grid system in the future, is constituted by a centralized power Grid system (the most bottom layer) associated with Grid-aware networks (the core Grid middleware layer), cloud-computing (the user middleware layer) and multi-purpose Grid applications (the Grid applications layer).

\section{Discussion and conclusion}

China's energy sources tend to suffer from geographical mismatch between supply and demand (Wang and Chen, 2010). Construction and development of power Grids in China tend to be sluggish (People's Daily, 2000; Fenby and Qu, 2008). China lacks a unified power Grid network across the nation and plans to set one up by 2020. The chief officer of the National Electric Company summed up his opinion as follows: "due to the differences in national condition, the future intelligent power Grid systems between China and the United States should differ considerably in aspects including development procedure, development direction and focal points". In addition, the vice president of National Grid Company emphasized that "first and foremost, the power Grid system in China should be a robust Grid; and based on current China's economic development and characteristics of geographical mismatch between supply and demand, building up an extra-high voltage power Grid with the characteristics of long-distance and high-capacity transmission becomes the most crucial target”. Further, the strategic energy expert of China, Jiang Dong $\mathrm{Wu}$, cited that "future intelligent power Grids will be upgraded from current power-focused Grids into synthesized and interactive Grids with functionality of power management, intelligent home appliance, building automation, electric transportation, telecommunication management and video entertainments. In other words, china will build up an electric fabric/cable synthesized Grid. This is going to be an industry even greater than $3 \mathrm{G}^{\prime}$. Then, the results of our estimated power Grid systems are consistent with their well-known discussion.

\section{References}

[1] Wang, Q., Chen, Y., 2010, Status and outlook of china's free-carbon electricity, Renewable and Sustainable Energy Review, 14, 1014-1025.

[2] Li, J., Gao, H., Shi, P., Shi, J., Ma, L., Qing, H., 2007, China wind power report in 2007. Beijing: China Environmental Science Press, 2007.

[3] Li, J., 2005, Wind force 12 in China. Beijing: Chemical Industry Press; 2005.

[4] CWERA, 2009, Center for wind and solar energy resources assessment, available from: http://cwera.cma.gov.cn/Website/index.php?ChannelID=39\&NewsID= 1434 .

[5] NDRC, 2007, Medium- and long-term nuclear development plan for renewable energy, Beijing, P.R. China: National Development and Reform Commission.

[6] World Nuclear Association (WNA), 2009, Nuclear Power in China, available from: http://www.world-nuclear.org/info/inf63.html.

[7] Fenby, J., Qu, D., 2008, China’s Grid power up, London: Trusted Sources UK Ltd.

[8] People's Daily, 2000, China to create nationwide power Grid network by 2020, People's Daily 2000. 
[9] Ma, H., Oxley, L., Gibson, J., 2009, China's energy situation in the new millennium, Renewable and Sustainable Energy Reviews, 13, 1781-1799.

[10] British Petroleum (BP), 2008, British Petroleum statistical review of world energy.

[11] Herrero, P., Katz, D.S., Perez, M.S., Talia, D., 2010, Special section: Grid computing, high performance and distributed applications, Future Generation Computer systems, 26, 257-258.

[12] Haque, A., Alhashmi, S.A., Parthiban, R., 2011, A survey of economic models in Grid computing, Future Generation Computer Systems, 27, 1056-1069.

[13] Globus, F.I., 2006, Toolkit version 4: software for service-oriented systems, Journal of Computer Science and Technology 21, 513-520.

[14] Rajkumar, B., Srikumar, V., Rajiv, R., 2009, The GRIDBUS middleware for market-oriented computing.

[15] Tom, G., Shantenu, J., Hartmut, K., John, S., 2008, SAGA: a simple API for Grid applications, High-level application programming on the Grid.

[16] Ian, T., Lan, W., Matthew, S., Shalil, M., 2005, Distributed computing with triana on the Grid, Concurrency and Computation: Practice and Experience, 1197-1214.

[17] Schweiegelshohn, U., Badia, R.M., Bubak, M., 2010, Perspectives on Grid computing. Future Generation Computer Systems, 26, 1104-1115.

[18] Izakian, H., Abraham, A., Ladani, B.T., 2009, An auction method for resource allocation in computational Grids, Future Generation Computer Systems, 26, 228-235. 